\title{
“JÁ PODE IR?": PRIMEIRAS IMAGENS DA LÍNGUA ALEMÃ ENTRE ESTUDANTES DE ALEMÃO PARA FINS PROFISSIONAIS
}

\section{"Can we go?":First images of German language amongst German for professional purposes students}

\author{
Alessandra de FREITAS \\ Universidade Federal do Paraná \\ freitasr.alessandra@gmail.com \\ https://orcid.org/0000-0001-6130-1745 \\ Carla Alessandra CURSINO \\ Universidade Federal do Paraná \\ cursino.carla@gmail.com \\ https://orcid.org/0000-0003-1648-6458
}

RESUMO: O presente trabalho é um recorte de uma investigação, de base qualitativa e com enfoque interpretativo, com um grupo de enfermeiros que aprendem a língua alemã para fins profissionais, na qual examinamos seus desenhos com o intuito de perceber quais imagens do idioma alemão eles possuem. Neste primeiro momento, discutimos o ensino de línguas para fins profissionais, com base em Kuhn (2007) e Prikoszovits (2017) e fundamentamos a concepção do curso em questão de alemão para a área da enfermagem. Por fazermos uso de métodos visuais como procedimento metodológico, ocupamo-nos da reflexão dos diferentes sentidos dos conceitos de imagem e representação (BOHUNOVSKY, 2005; COELHO; SIMÕES, 2017; DIAS, 2007) e do desenho como objeto de análise (MELO-PFEIFER; SIMÕES, 2017). Analisamos três produções visuais, levando em conta não só os ícones presentes, bem como expressões verbais que os acompanham e também comentários feitos pelos aprendizes ao exibirem suas ilustrações. $\mathrm{Na}$ análise pudemos perceber que as imagens da língua alemã podem ser interpretadas a partir de três categorias: i) a língua enquanto imagem cultural associada a um único país; ii) língua como objeto de ensino-aprendizagem e de sucesso profissional e, iii) língua enquanto objeto afetivo e de projeção pessoal. PALAVRAS-CHAVE: Ensino de língua para fins profissionais. Alemão como Língua Estrangeira. Métodos Visuais. 


\begin{abstract}
This paper is a fragment of a research, on a qualitative basis and with an interpretative focus, with a group of nurses who learn German for professional purposes, in which we examine their drawings in order to understand which images of German language they have. At first, we discuss language teaching for professional purposes, based on Kuhn (2007) and Prikoszovits (2017) and we build up the conception of the German course for nursing. Since we use visual methods as a methodological procedure, we are concerned with the reflection upon different meanings of the concepts of image and representation (BOHUNOVSKY, 2005; COELHO; SIMÕES, 2017; DIAS, 2007) and drawing as object of analysis (MELO-PFEIFER; SIMÕES, 2017). We analyse three visual productions, considering not only the icons, but also verbal expressions that accompany them and the comments made by students when displaying their illustrations. In the analysis, we could see that the images of German language can be construed as three categories: i) the language as a cultural image associated with a single country; ii) language as an object of teaching-learning and professional success; and iii) language as an affective object and personal projection.
\end{abstract} KEYWORDS: Language teaching for professional purposes. German as a foreign language. Visual methods.

\title{
INTRODUÇÃO
}

Dentre as muitas motivações existentes para se iniciar o aprendizado de uma língua estrangeira, certamente a motivação profissional figura hoje como uma das principais. Isso acontece não só pelo fato de que falar mais de um idioma é, por um lado, uma necessidade em algumas áreas e, por outro, consiste em uma qualificação que contribui para uma melhor colocação no mercado de trabalho, mas também porque em determinados setores há uma maior demanda por mão de obra qualificada, a partir da qual, tendo em vista as configurações impulsionadas pela globalização, podem ser estabelecidas relações entre diferentes países em diferentes línguas.

Neste contexto, há alguns anos a Alemanha vem buscando profissionais de enfermagem para além de suas fronteiras (como no Brasil, México, Vietnã, entre outros) para trabalharem nas Universitätskliniken (hospitais universitários). Uma parte importante do processo de recrutamento destes trabalhadores, que é intermediado por agências privadas, consiste em um curso superintensivo de alemão - com duração de 6 a 8 meses - e na obtenção do certificado oficial de proficiência no idioma em questão elaborado 
pelo Goethe Institut, a saber Goethe Zertifikat B1 ${ }^{1}$. Muitas enfermeiras e enfermeiros que decidem participar deste processo se deparam com o compromisso de aprender esta língua em um curto espaço de tempo, o que representa, por assim dizer, o começo de uma mudança em sua trajetória profissional.

Quais imagens os profissionais de enfermagem possuem da língua alemã e de que forma elas se relacionam com seus objetivos profissionais é o que buscamos discutir brevemente neste artigo. Apresentamos aqui resultados iniciais e parciais de uma pesquisa que está sendo desenvolvida com esse público, na qual investigamos desenhos de enfermeiras e enfermeiros que se encontram no processo de aprendizado de alemão, para examinarmos que representações deste idioma eles apresentam e como estas influenciam seu aprendizado da língua.

Estudos inseridos na área de Didática das Línguas (DL) (COELHO; SIMÕES, 2017; DIAS, 2007; MELO-PFEIFER; SCHMIDT, 2014, entre outros) afirmam que as imagens/representações das línguas desempenham um papel fundamental no aprendizado de um novo idioma. São estudos que apontam o fato de essas imagens serem, muitas vezes, justamente o ponto de partida da relação subjetiva que cada sujeito vai estabelecer com a(s) língua(s) em questão, influenciando, por exemplo, na escolha de qual idioma aprender e/ou no próprio processo de aprendizagem.

Para dar conta de apresentar os resultados de nossa investigação, organizamos a presente contribuição da seguinte forma: em um primeiro momento, discutiremos o ensino de línguas para fins profissionais, particularmente, o caso de cursos de alemão, com base em Kuhn (2007) e Prikoszovits (2017). Também mobilizaremos Coelho e Simões (2017), Dias (2007) e Bohunovsky (2005) para tecer algumas noções acerca da imagem e representações linguísticas na DL. Na sequência, apresentaremos o projeto no qual este trabalho se inscreve, bem como a metodologia empregada em nossa pesquisa. Posteriormente, discorreremos sobre os resultados obtidos e as análises realizadas a partir dos dados gerados pela pesquisa. Finalmente, sintetizaremos nossas considerações finais, limitações e perspectivas futuras para o presente estudo.

\section{ENSINO DE LÍNGUAS PARA FINS PROFISSIONAIS E O CURSO DE ALE- MÃO PARA A ÁREA DA ENFERMAGEM}

O contexto do presente estudo envolve um curso superintensivo de alemão para profissionais da área da enfermagem. Tendo isso em vista, nesta seção, pretendemos

\footnotetext{
${ }^{1}$ A depender da empresa e da Universitätsklinik, é necessário obter o Goethe Zertifikat B2. 
nos debruçar sobre a seguinte questão: o que caracteriza o ensino de línguas para fins profissionais? Dentro da área de Alemão como Língua Segunda e Estrangeira a discussão sobre o ensino da língua voltado para fins laborais tem ganhado importância desde a década de 1990. Nesse debate, uma das reflexões centrais tem sido definir em que momento do aprendizado a especificidade linguística de cada área profissional deve ser o foco. Para compreender melhor essa questão, Kuhn (2007) e Prikoszovits (2017) apresentam as noções de: i) linguagem comum (Allgemeinsprache); ii) linguagem profissional (Berufssprache); iii) linguagem técnica (Fachsprache)2.

A linguagem comum seria aquela utilizada no dia a dia na comunicação entre as pessoas. Ela transita entre a oralidade cotidiana e a escrita padrão e está presente em muitos contextos. Segundo Prikoszovits (2017), embora não seja um conceito bem definido e amplamente utilizado, a linguagem comum seria o registro mais frequentemente empregado nas aulas de línguas estrangeiras. Em consonância com Funk (2010 apud PRIKOSZOVITS, 2017), é possível afirmar que uma parte importante da comunicação profissional cotidiana consiste em ações linguísticas que não são específicas de um ramo profissional e a linguagem comum pode ser usada como base lexical, gramatical e pragmática para todas as outras variedades e registros.

A linguagem profissional, por outro lado, seria aquela usada por diferentes grupos profissionais e compreende as especificidades linguísticas de cada ocupação bem como as formas utilizadas por cada empresa/instituição específica, embora não tenha uma forma estandardizada definida. Prikoszovits (2017), apoiado em outros autores, afirma que ela se diferencia da linguagem técnica, na medida em que esta última imprime um nível de abstração maior na sua utilização, enquanto a anterior expressaria um nível de abstração menor. Segundo Efing (2014, p. 429 apud PRIKOSZOVITS, 2017, p.3), a linguagem profissional, oral e escrita, estabelece-se em um contínuo entre a linguagem comum e a linguagem técnica.

Por sua vez, a linguagem técnica seria o modo de comunicação de diferentes disciplinas e surge como um produto da socialização destas. Ela reflete certas estruturas de pensamento que são também definidas pelos métodos de cada área e, além disso, é dominada por especialistas de cada campo de estudo e funciona como um registro da comunicação entre eles, possuindo um caráter instrumental. Kuhn (2007), valendo-se da contribuição de outros autores, argumenta que a linguagem técnica, assim como a profissional, pode ser entendida como uma sublinguagem da linguagem comum. Dentro deste entendimento,

\footnotetext{
${ }^{2}$ Prikoszovits (2017) também versa sobre o conceito de Bildungssprache (linguagem de instrução), o qual não abordaremos neste trabalho, por ele estar mais associado a instituições formais de ensino, como a escola.
}

Revista X, v. 16, n. 2, p. 586-607, 2021. 
o que define a linguagem técnica é menos um suposto vocabulário técnico, embora ele esteja presente, e mais a participação de especialistas na área bem como objetivo da comunicação, que é predominantemente limitado a troca de conhecimentos (p. 107).

Os dois autores mencionam o argumento de Funk (2010 apud PRIKOSZOVITS, 2017) de que a competência comunicativa de um sujeito não pode ser dividida em uma dimensão privada e outra profissional, mas que ela encontra sua expressão justamente em lidar com diferentes situações em diferentes campos de atividades. Neste sentido, embora os limites que definem cada uma destas linguagens não sejam nitidamente bem demarcados, ao que se considera linguagem comum, isto é, aquela não é específica nem exclusiva de cada área de atuação, é atribuída uma função mais significativa no aprendizado da língua, enquanto a especificidade da linguagem profissional/ técnica, seja a nível lexical ou pragmático, complementa este aprendizado para suprir as necessidades linguísticas particulares da área profissional do aprendente ou do grupo de aprendentes.

Segundo Prikoszovits (2017) o ensino de língua estrangeira voltado para fins laborais deve estar direcionado para a integração da linguagem comum e da linguagem profissional. Ele parte do modelo das pirâmides opostas de Funk (2001 apud PRIKOSZOVITS, 2017) e sugere ampliá-lo, com base em fases e níveis de competência levando em conta as diretrizes propostas pelo Quadro Europeu Comum de Referência para as Línguas (QECR). Dentro deste modelo, uma das pirâmides representa a parte do ensino de língua que corresponde ao ensino dos elementos da linguagem comum e a outra, da linguagem profissional. A proposta de Prikoszovits pode ser ilustrada pela figura a seguir:

Figura 1: Modelo das pirâmides opostas em relação aos níveis do QECR.

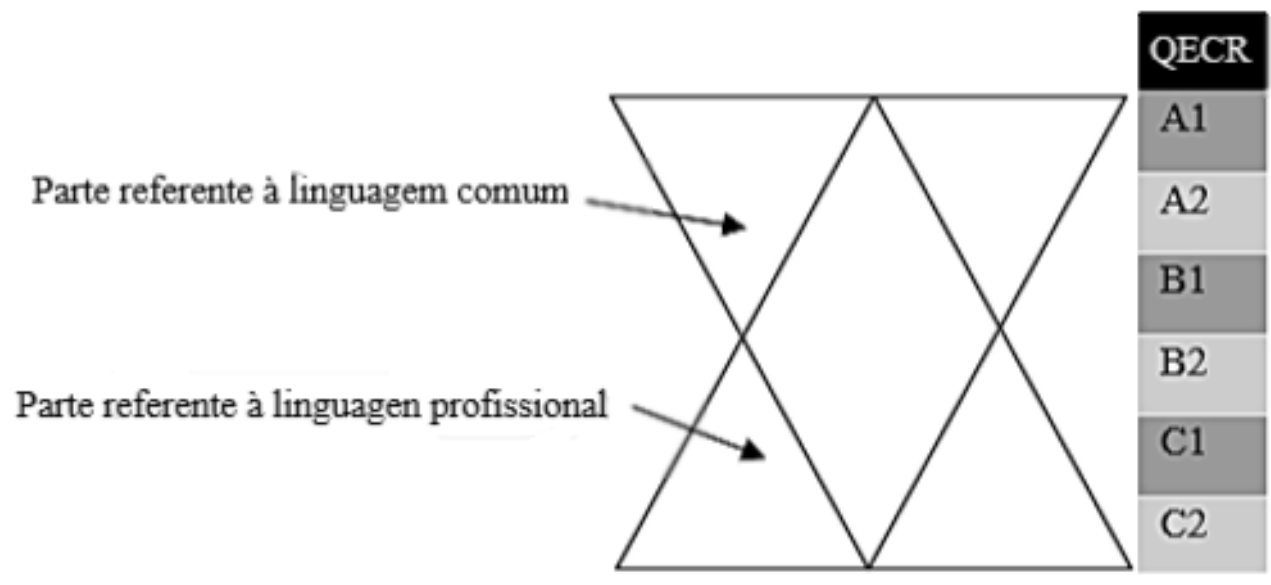

Fonte: Prikoszovits (2017, p. 159) - Tradução nossa. 
\#PraCegoVer: Imagem gráfica: um losango ao centro, na parte superior dois triângulos se encaixam em suas laterais. Outros dois triângulos se encaixam em suas laterais inferiores. Nos triângulos de cima a indicação "Parte referente à linguagem comum" e nos triângulos de baixo "Parte referente à linguagem profissional". Ao lado uma tabela na vertical indica os níveis QECR, A1, A2, B1, B2, C1, C2.

Ao associar o modelo de Funk com o QECR, o autor busca contextualizar esse entrelaçamento entre as linguagens em um eixo temporal, o que pode servir de base para pensar currículos dos cursos de línguas voltado a profissionais, sejam eles contínuos, isto é, que compreendem o aprendizado da língua desde os níveis iniciais, ou ainda cursos complementares. Na figura, é possível perceber que a linguagem comum embasa o ensino inicial da língua estrangeira e é predominante até o nível intermediário B1. Somente a partir do nível B2, os elementos da linguagem profissional aparecem de modo mais evidente, e a linguagem comum começa a ceder espaço para as especificidades linguísticas de cada ocupação distinta. No entanto, ele também mostra que componentes da linguagem profissional podem ser inseridos já nos primeiros níveis.

Apoiamo-nos nas reflexões feitas por Prikoszovits (2017) a fim de elucidar a proposta do curso de alemão para profissionais de enfermagem em questão. Acreditamos na relevância de abarcar a linguagem específica da área, na qual os aprendizes atuam, no entanto, a linguagem comum é quem desempenha um papel central no processo ensinoaprendizagem e na mediação de temas. Ainda que seja um curso voltado para fins laborais específicos, nossa atenção acaba direcionando-se principalmente para prepará-los para a prova de proficiência do nível B1 - um dos pré-requisitos para que eles possam ir para a Alemanha. Este aspecto gera um efeito retroativo, pois o teste de certificação aborda temas mais gerais e não particulares do campo da enfermagem. Sem dúvida, componentes da linguagem profissional aparecem já no início do aprendizado, uma vez que o falar sobre si é muito importante nos primeiros níveis - e no caso destes profissionais, contar sobre si implica também mencionar suas atividades laborais - porém ela não ocupa um lugar de destaque ao longo do curso, justamente por este abarcar os três primeiros níveis do QECR (A1, A2 e B1), não compreendendo, em um primeiro momento, os níveis avançados nos quais, por já se ter uma base da linguagem comum, a linguagem profissional poderia figurar como principal.

Deste modo, após esta breve explanação sobre o ensino de línguas para fins profissionais na área de Alemão como Língua Estrangeira, abordaremos a seguir as noções de imagens e representações das línguas no campo de estudos da linguagem. 


\section{IMAGENS E REPRESENTAÇÕES LINGUÍSTICAS NO CAMPO DA DIDÁ- TICA DAS LÍNGUAS}

Começamos esta seção com algumas considerações acerca das metodologias visuais, notadamente as voltadas para o ensino-aprendizagem de línguas. Moore (2017) ressalta que tal método proporciona uma abordagem interessante dos locutores-atores do funcionamento e dos valores atribuídos aos idiomas. Contudo, tal noção é um conceito que apresenta várias perspectivas de leitura, sendo, portanto, necessária uma breve discussão de algumas destas interpretações para apontar a acepção de imagem/representação que estamos utilizando neste trabalho.

Coelho e Simões (2017), em consonância com outros autores, discutem em um primeiro momento o fato de os conceitos "imagem" e "representação" serem usados como sinônimos, sobretudo porque são termos empregados não só na área de DL, como também em outras disciplinas como Antropologia, Sociologia etc. Por circularem em muitos campos de estudo eles são, segundo as autoras, "ambíguo[s], sem estabilidade semântica e terminológica" (COELHO; SIMÕES, 2017, p. 34), e muitas vezes são utilizados com a acepção de representação social, estereótipo, crenças, entre outros.

Quando se trata de imagens das línguas, alguns autores argumentam sobre o fato de estas imagens serem "resultados" de processos sociais, históricos e culturais dinâmicos. De maneira sintética, Coelho e Simões afirmam que:

as imagens são o produto de uma construção coletiva e social, que se adaptam a várias situações, são processos históricos, socioidentitários, cognitivos e discursivos próprios de cada indivíduo ou grupo, fazem parte da língua para que possam organizar e categorizar o mundo, de forma a serem utilizadas através do discurso, uma vez que influenciam o modo como os sujeitos interagem com a realidade (COELHO; SIMÕES, 2017, p.35).

Nesse sentido, Dias (2007) se baseia em Matthey (1997) para afirmar que as metodologias visuais, independentemente da perspectiva teórica na qual se ancoram, servem todas para levar à compreensão de como as representações linguísticas são construídas, de quais funções desempenham e de suas relações com o contexto social. O que se verifica, de acordo com Coelho e Simões (2017), é que as imagens de uma língua estrangeira tendem a apresentar-se aos sujeitos antes do início do seu processo de aprendizado e inevitavelmente desempenham um papel importante nesse percurso.

Bohunovsky (2005) aborda a questão das imagens das línguas, mais especificamente da língua alemã, a partir da noção de imaginário, que é construído e Revista X, v. 16, n. 2, p. 586-607, 2021. 
veiculado por discursos e ideologias. A autora parte da perspectiva da Linguística Aplicada Crítica (cf. PENNYCOOK 1999) e mobiliza as noções de ideologia e discurso como processos de significação. A ideologia seria as formas pelas quais as ideias dominantes são sustentadas, enquanto discurso é entendido como uma prática social, que constrói tanto os sujeitos, quanto os objetos de conhecimento, bem como as relações entre eles e a realidade (p. 329). Nesse sentido, a ideologia constitui-se como "a direção nos processos de significação e se sustenta no fato de que o imaginário que institui as relações discursivas é político" (ORLANDI, 1990, p.36 apud BOHUNOVSKY, 2005, p.329). Aqui é importante mencionar que o uso do "político' não diz respeito a uma esfera pública da vida social, mas às relações sociais presentes em nosso cotidiano, que são também marcadas por ideologias. Um exemplo de representação linguística da língua alemã sustentada ideologicamente é o imaginário já bastante estabilizado de que o alemão é uma língua mais "culta” e "difícil” (p.333). De acordo com Bohunovsky, essa qualificação atribuída à língua alemã acaba realçando um suposto caráter de superioridade, enquanto, por outro lado, destaca uma suposta inferioridade da língua e cultura brasileiras. Mesmo que atualmente possa não haver alguém que sustente amplamente a falsa superioridade da língua alemã, essa noção ainda se mantém porque é resultante de processos históricos, nos quais discursos são também espaços de disputa.

Em consonância com alguns autores (cf. CALVET, 1998; BOYER, 1996), Dias (2007) salienta que as representações linguísticas, uma vez que agem sobre as práticas, estabelecem juízos de valor, bem como as posições ideológicas dos sujeitos refletem sobre as línguas e suas variedades. A partir delas, os indivíduos podem produzir percepções e realizar avaliações com base em estereótipos sociais, que, por sua vez, podem conduzir a comportamentos de segurança / insegurança, de hipercorreção linguística ou de que aprender determinado idioma é um processo árduo e difícil quando comparado a outros.

É inevitável, portanto, que os aprendizes de línguas estrangeiras levem consigo para a sala de aula suas pré-concepções relacionadas a outras línguas e culturas. Diante disso, "é importante que os alunos sejam sensibilizados para a construção de atitudes e motivações que os tornem mais responsáveis e cooperantes nas suas relações" (DIAS, 2007, p. 54). Na visão da autora, cabe aos professores saber como reagir às opiniões e pré-conceitos de seus estudantes. Além disso, os docentes devem manter em perspectiva que o imaginário inicial de cada aprendente pode ser aumentado, estabilizado ou questionado ao longo do processo de aprendizado. Nesse sentido, o professor deve, por meio do questionamento, perceber qual é a relação de proximidade 
ou de afastamento do aprendiz com a língua alvo ao longo do processo de aprendizagem, conforme Coelho e Simões (2017).

Após esta breve discussão teórica sobre os conceitos de imagem e representação linguística, nos cabe colocar que a presente contribuição toma o termo "imagem" a partir de duas concepções, a saber: i) como marco teórico que explica, conforme explanado nos parágrafos anteriores desta seção, a relação dos sujeitos com línguas e culturas relação esta construída no e pelo discurso; ii) como método de geração de dados. Sobre a segunda concepção, "imagem" faz referência à produção icônica voltada a um tema específico (MELO-PFEIFER; SCHMIDT, 2014). Em nosso estudo, como ficará mais claro adiante, partimos da coleta de desenhos realizados por estudantes em fase inicial de aprendizagem do alemão para verificar as representações sociais acerca desta língua e que lugar ela ocupa no repertório linguístico desses sujeitos. É importante ressaltar que o presente trabalho aborda uma parte inicial, isto é, um primeiro questionamento das imagens que aprendentes de alemão em um contexto específico possuem deste idioma, e que pretendemos continuar a investigação ao longo da aprendizagem. Detalharemos na sequência nossa metodologia.

\section{METODOLOGIA E RECOLHA DE DADOS}

\section{$O$ contexto da pesquisa e perfil dos aprendentes}

Como já dito anteriormente, o presente estudo busca apreender, a partir da análise de desenhos, as imagens que aprendentes de alemão em fase inicial possuem da língua. Estes estudantes são, por sua vez, profissionais de enfermagem que estudam o idioma com o objetivo específico de poder exercer sua atividade laboral na Alemanha. Deste modo, antes de apresentarmos os procedimentos metodológicos utilizados na investigação, gostaríamos de expor brevemente como é organizado o curso e apresentar o perfil dos estudantes.

O curso conta com uma carga-horária de 815 horas, distribuídas em 7 meses, e foi planejado para uma turma de 15 profissionais da área de enfermagem, a maioria com nível iniciante em língua alemã. Sendo assim, do início ao fim, o curso contempla três níveis de acordo com o QECR, a saber os níveis A1, A2 e B1. Por conta da pandemia instaurada pelo SARS-COVID-19 e pelas medidas sanitárias implantadas com o objetivo de conter o contágio do vírus, o curso que, inicialmente, seria presencial, precisou ser adaptado a uma versão digital, e desde o início aconteceu integralmente online, com a mesma carga horária. As aulas acontecem sincronicamente, de segunda à sexta no período da manhã, 
mas há também atividades assíncronas para os aprendizes. Embora já existam materiais didáticos específicos voltados para o ensino de alemão para a área da enfermagem, optouse por utilizar uma série de livros didáticos convencional para a mediação dos temas a serem tratados em sala, que são complementados por outros materiais disponíveis.

O curso é conduzido por três professoras, todas com graduação e pós-graduação na área de Letras, sendo uma delas já doutora, outra em fase de doutoramento e a terceira, mestre. Desse modo, são professoras que compreendem não só a importância do ensino, mas também da pesquisa e que esses dois componentes caminham juntos no aprendizado de uma língua estrangeira. As docentes dividem a carga horária das aulas, além de se encontrarem semanalmente em uma reunião virtual pedagógica, a fim de discutir o andamento do curso, bem como fazer o acompanhamento do grupo e de cada aprendiz individualmente.

O grupo, por sua vez, é formado por 15 profissionais de enfermagem, já atuantes em suas áreas, dos quais a maioria é do gênero feminino. A faixa etária varia de 25 a 48 anos e são estudantes que vêm de diferentes regiões do Brasil. Até o início do curso, o grupo tinha tido majoritariamente pouco contato com a língua alemã, estudando autonomamente, embora uma pequena parcela (3 profissionais) já tivesse feito um curso de alemão anteriormente.

Ainda é importante apontar que o processo seletivo destes profissionais, bem como os procedimentos a serem feitos até que eles assumam seus postos de trabalho na Alemanha é feito pela agência responsável em cooperação com a Universitätsklinik, na qual estes estudantes atuarão profissionalmente. Às professoras cabem somente a organização e realização do curso, além do acompanhamento pedagógico, conforme já mencionado. Uma vez alcançada a certificação no idioma e após a concessão do visto, estes aprendizes partem então para a Alemanha e, antes de iniciarem suas atividades laborais, passam por um curso de preparação para fazer a prova do nível B2.

Sendo assim, após este breve panorama do contexto e sujeitos da pesquisa, passemos à apresentação dos caminhos metodológicos da pesquisa e como se deu o processo de recolha de dados.

\section{Procedimentos metodológicos}

O estudo que ora apresentamos constitui parte inicial de uma pesquisa que está sendo desenvolvida com o grupo descrito ao longo do curso de alemão. O que nos motiva, conforme já exposto anteriormente, é pensar quais as associações que os aprendentes fazem com a língua alemã e de que maneira essas imagens/representações influenciam no Revista X, v. 16, n. 2, p. 586-607, 2021. 
seu processo de aprendizado do idioma, numa perspectiva diacrônica. Isto é, recolhemos esses primeiros dados na etapa inicial do curso e nossa proposta é refazer o mesmo exercício na fase final do processo, a fim de perceber que mudanças ocorreram no tocante às imagens e representações que os sujeitos da pesquisa possuem da língua alemã. Esta investigação, de natureza qualitativa, assume contornos de um estudo de caso e, além disso, a análise dos dados possui um enfoque interpretativo.

Como mencionado anteriormente, as produções visuais dos aprendizes foram escolhidas como instrumento de recolha de dados. Apesar de ser um meio ainda pouco difundido, mas já utilizado em outros trabalhos na área da DL, o desenho como recurso metodológico apresenta uma perspectiva multimodal para um campo de estudo que foca e valoriza sobretudo o discurso verbal - seja mediado pela escrita ou pela oralidade-e propõe o desafio de se investigar outras formas de discursividade, a partir de uma perspectiva semiótica, em que o objeto central de investigação, embora esteja em diálogo com outras elementos verbais, é um objeto visual (MELO-PFEIFER; SIMÕES, 2017, p.18). Em relação a pesquisas que se dedicam a examinar as representações das línguas, o desenho, segundo Coelho e Simões (2017), possibilita ter acesso a uma imagem real das línguas e do imaginário dos aprendizes, ainda que possua traços muito subjetivos. Os desenhos, neste trabalho, atuam como mediadores entre os sujeitos e suas concepções de língua, contribuindo para identificar as representações sociais acerca da língua alemã.

Os dados foram recolhidos no mês de maio de 2020, na segunda semana de aula do curso. Neste dia, do grupo de quinze, nove estudantes estavam presentes e eles deveriam desenhar em uma folha a resposta para a seguinte questão: "De que vocês se lembram ou que associações vocês fazem quando pensam na língua alemã?’. Alguns desenhos também vêm acompanhados de produções escritas (palavras ou frases em português e/ ou em alemão) redigidas de modo espontâneo, isto é, a partir do próprio entendimento do comando por parte dos aprendizes. Após a tarefa de ilustrar, cada aluno pôde mostrar o que fez e então compartilhar o porquê de ter desenhado tais elementos. As anotações dessas observações também serão utilizadas na análise, quando oportuno. Faz-se necessário mencionar que, porque o curso acontece digitalmente, não foi possível padronizar a folha em que os desenhos foram feitos, bem como a digitalização das imagens ficou condicionada aos aparelhos que os próprios estudantes tinham à disposição.

A análise dos dados busca, neste primeiro momento, identificar as imagens que os aprendentes possuem da língua alemã e observar o que elas podem indicar sobre o aprendizado da língua por parte dos estudantes. Por este estudo ser um recorte de uma pesquisa que está em sua etapa inicial, optamos por não estabelecer ainda categorias de 
análise a priori, mas de i) fazer uma análise dos ícones presentes nos desenhos e suas representações sociais de acordo com o que foi descrito anteriormente, ii) complementálas com os comentários dos aprendizes sobre suas próprias produções, a partir disso, iii) perceber se destas elaborações despontam categorias e, se isso ocorrer, iv) identificá-las. Ademais, por buscarmos fazer uma análise mais detalhada de cada produção levando em conta os procedimentos metodológicos acima citados, por não se tratar de um estudo de base quantitativa e, ainda, por questões de delimitação de espaço, optamos por apresentar a análise de três desenhos, que se mostram também representativos das considerações expostas por todos os sujeitos durante a atividade.

\section{ANÁLISE DOS DADOS}

Como já mencionado, para identificarmos as imagens que os aprendizes possuem da língua alemã, foi pedido que eles expressassem em forma de desenho o que eles lembravam quando pensavam na referida língua ou quais associações eles faziam com ela. A primeira questão que achamos relevante mencionar é que, no momento em que os estudantes compartilhavam suas produções, muitos retomavam a questão proposta substituindo "língua alemã" por "Alemanha". Ou seja, muitos deles compreenderam que a atividade se tratava de desenhar as associações que eles faziam com a Alemanha e não com língua alemã. A partir dessas observações, podemos afirmar que uma das primeiras imagens que os aprendentes têm da língua alemã é a de uma língua monocêntrica - em oposição ao termo pluricêntrico (AMMON, 2015) -, isto é, uma língua que possui uma única variação padrão proposta por um centro, neste caso, a Alemanha. Dessa forma, para eles, falar da língua alemã significa necessariamente falar da Alemanha, o que fica nítido nas produções com alguns desenhos, principalmente os da bandeira alemã.

Na primeira produção visual (anexo 1), há uma série de ícones que compõem essas imagens da língua. No canto superior esquerdo aparecem as bandeiras da Alemanha e do Brasil e um avião que, a partir do tracejado, é possível perceber que ele "parte" da bandeira brasileira em direção à bandeira alemã. Embaixo delas está escrito o nome do país em questão na língua alemã, bem como abaixo da imagem do avião está escrito "Flugzeug", a palavra alemã para tal meio de transporte. Essa imagem pode ser associada ao fato que, após o curso, os aprendizes irão viajar para a Alemanha para seguirem com sua atividade profissional neste país. Tal elemento está presente na maior parte das produções e caracterizado principalmente pelo símbolo do avião e/ou malas de viagem. Ele indica, nesse sentido, o fim específico para o qual os profissionais estão aprendendo a língua, a saber, trabalhar como enfermeiros na Alemanha. Complementando esta referência, Revista X, v. 16, n. 2, p. 586-607, 2021. 
no centro da folha mais à direita há a figura de uma pessoa e um balão, utilizado para expressar pensamentos, onde está a pergunta “já pode ir?”, em alusão à chegada da viagem, segundo informações da própria aluna quando compartilhava sua produção.

Ainda associado ao exercício laboral em território germânico, próximas a esta figura acima descrita estão as imagens de um hospital e uma ambulância, com as respectivas traduções para o alemão "Krankenhaus" e "Krankenwagen". Durante suas observações, a aluna relata que, no âmbito da enfermagem, ela tem preferência por trabalhar como enfermeira socorrista, isto é, a que atua no atendimento pré-hospitalar móvel e em espaços fora do hospital, por isso, além deste, também a figura da ambulância.

Outros elementos importantes do desenho são as imagens relativas às festividades, que estão representadas pela bailarina na parte central superior da folha e pelo caneco de cerveja, encontrado na parte inferior à esquerda da imagem. A bailarina vem acompanhada da frase alemã "ein Prosit!”, que corresponde à expressão "saúde!” (quando se brinda), como se a bailarina mesma oferecesse um brinde. Além disso, a figura da cerveja é complementada por "das Bier", que significa de fato "a cerveja". Aliado a isso, há também a imagem de uma comida, pão com uma salsicha, cuja descrição está em inglês, "hot dog".

$\mathrm{O}$ desenho apresenta ainda outros componentes que fazem referência a processos históricos, pelos quais o que hoje é entendido como o país Alemanha passou. No canto esquerdo inferior há uma suástica no interior de um círculo; sobre ela repousa um " $\mathrm{x}$ " em vermelho, em alusão a uma negação ou a algo que é proibido. Em cima da figura, há, em português, a expressão "nazismo". Aqui a aluna faz também uma associação negativa à língua, em referência à ideologia nazista que imperou no século passado, no território germânico, no período anterior e também durante a Segunda Guerra Mundial. Ao lado desta, aparece o desenho de um muro, descrito acima como o "Muro de Berlim", barreira física que dividiu as então Alemanhas oriental e ocidental no pós guerra. Mais distante destes ícones, no canto superior direito, há a imagem de um castelo, com esta mesma palavra logo embaixo, um ícone que representa um elemento arquitetônico, mas que também faz alusão a épocas anteriores.

Há ainda um componente na produção visual que estabelece uma relação entre Brasil e Alemanha; essa ligação está representada por uma bola de futebol e ao lado um placar, no qual se pode ver "7x1". Aqui a referência à Copa do Mundo de Futebol, sediada no Brasil em 2014, na qual em um confronto entre as seleções brasileira e alemã, a equipe alemã venceu por 7 gols, contra somente 1 do Brasil. Este é o único ícone do desenho em que não há uma descrição, uma palavra que o ilustre. 
No centro da página, por fim, temos uma referência mais explícita à língua alemã; ali há a ilustração de uma pilha de livros e embaixo está escrito "Deutsch", ou seja, "alemão", indicando que a língua alemã diz respeito ao contato com livros, à leitura e à escrita. Na apresentação do desenho a aluna, ao fazer referência à imagem do livro, diz que para aprender alemão é preciso estudar muito.

$\mathrm{Na}$ segunda produção (Anexo 2), alguns elementos se repetem. Estes são: o caneco de cerveja, no canto superior direito da imagem, complementado com uma seta que aponta para a descrição em português. Logo abaixo dele há a ilustração de um "Dirndl", roupa típica feminina da região da Baviera, local de origem da "Oktoberfest", que são tradicionalmente usadas tanto na Oktoberfest em território alemão, como na realizada na cidade de Blumenau, em Santa Catarina, bastante conhecida no Brasil. No desenho, esta imagem vem acompanhada das palavras "festa", indicada com uma seta ao lado, e "Octoberfest", embaixo. Outro ícone reproduzido é a ilustração de um avião, seguido da palavra "viagem", ao lado direito. Ao relatar a própria produção, a aluna menciona o desenho do avião e a palavra viagem não só porque ela gosta de viajar, mas principalmente, por acreditar que partir para Alemanha para trabalhar lá seria a realização de um sonho pessoal.

Neste desenho, há ainda a ilustração de uma casa no estilo enxaimel, arquitetura tradicionalmente associada a casas típicas da Alemanha, adornada por flores. Na parte superior é possível ver a palavra "Arquitetura". Ao comentar esta ilustração, a aluna declara associar à arquitetura beleza e muitas cores, por isso ela também deixou o desenho colorido. Todos os ícones nesta produção estão separados entre si por linhas e no canto superior direito percebe-se uma separação onde não há nada ilustrado, mas sim uma lista de palavras ou expressões iniciadas por hífen, as quais reproduzimos na ordem aqui: flores; história da cultura alemã (estas duas últimas palavras estão sublinhadas); festa; bebida; viagem. Este último termo é seguido de um hífen, o qual não vem acompanhado de nenhum vocábulo, indicando possivelmente uma continuidade de palavras que poderiam estar ali.

Por fim, na terceira produção visual (Anexo 3) temos a imagem de um troféu no centro, ao lado dele a ilustração de uma pessoa com um chapéu e uma cruz ilustrada, indicando que se trata de uma enfermeira, o que é confirmado pela descrição ao lado: "eu enfermeira", ou seja, há ali uma autorreferenciação, como acontece também no desenho do anexo 1. Ainda próximo a esta figura, observa-se o que parece ser um balão de diálogo ou pensamento, típico de histórias em quadrinhos, e nele está escrito a palavra "sonho". Logo acima está ilustrada a bandeira da Alemanha, um elemento também presente na primeira produção, pintada com as cores preto e vermelho, porém, pelo fato de aluna 
não dispor de uma caneta e/ou lápis da cor amarela no momento, ela escreve "amarelo" dentro da bandeira, substituindo a cor pelo seu nome. Ao ser perguntada sobre sua produção, a estudante informa que o troféu representa uma conquista, a saber, conseguir falar alemão; ele também ilustra o fato de isso ser percebido por ela como um desafio. Além disso, ao se desenhar enfermeira, ela expõe que aprender alemão e trabalhar como profissional de enfermagem na Alemanha significa a realização de um sonho. Mais uma vez, identifica-se a associação da aprendizagem da língua alemã à motivação pessoal e à ideia de ascender socialmente.

Com base na identificação dos elementos presentes nas três produções, é interessante notar, em um primeiro plano, a necessidade da linguagem verbal - seja em alemão, português ou inglês - pois quase todos os desenhos vêm acompanhados de uma descrição; além disso, também é possível perceber em todas as produções a repetição de alguns componentes. Podemos, ainda, encaixar os ícones desenhados em três grandes categorias ${ }^{3}$ : a primeira, já descrita no início desta seção, língua enquanto imagem cultural associada a um único país, que diz respeito à língua alemã na sua relação direta com a Alemanha e sua cultura - que foi bastante citada nos comentários dos aprendizes ao apresentarem seus desenhos. Nas produções ela está representada não só pela bandeira alemã, mas também associada a alguns produtos culturais e/ou estereótipos já comumente relacionados à Alemanha ${ }^{4}$, como as festividades, o caneco de cerveja, a comida, a "Oktoberfest", ou ainda a arquitetura e também à história do país, a qual foi assinalada com figuras, por exemplo, o Muro de Berlim no desenho do anexo 1, mas também verbalmente, como pode ser vista na produção no anexo 2, em que há a expressão "história da cultura alemã".

A segunda categoria, língua como objeto de ensino-aprendizagem e de sucesso profissional, tem a ver com a língua alemã enquanto objeto de estudo, representada pela pilha de livros, de um lado, e, de outro, entendida como um êxito conquistado, sinalizado pelo troféu. Essas duas representações atribuem a língua alemã uma caraterística de processo, isto é, falar alemão está intimamente ligado a investir tempo, concentração e esforço pessoal para a realização de tal empreendimento, assim como o é ao conquistar um troféu, em qualquer área. Tanto os elementos presentes no desenho quanto as

\footnotetext{
${ }^{3}$ Definimos as três categorias principais mencionadas na presente contribuição com base em Coelho e Simões (2017), mas com algumas adaptações necessárias por conta de nosso contexto de atuação e desenvolvimento de pesquisa.

${ }^{4}$ Para além de estereótipos, os elementos colocados pelas estudantes em suas produções integram parte da paisagem linguística (cf. SHOHAMY; WAKSMAN, 2012) do sul do Brasil, região que conheceu forte imigração alemã no século XIX e XX e onde se encontram traços culturais da Alemanha, como na arquitetura, em festividades, restaurantes e bares.
} 
explicações dadas pelas estudantes que os produziram nos permitem perceber o préconceito da língua alemã como "difícil", como discorre Bohunovsky (2005), e quem a aprende é digno de um prêmio.

A terceira categoria, por fim, língua enquanto objeto afetivo e de projeção pessoal, corresponde a uma dimensão afetiva, de relação das aprendizes com a língua alemã, que está, por sua vez, associada à realização de um sonho pessoal, como comentado pela maioria, que é o exercer sua profissão na Alemanha. Esta noção é ilustrada pelas figuras de avião, hospital, ambulância e os desenhos representativos de si. É interessante notar que nesses casos em que se percebe as imagens da língua alemã associadas ao deslocamento (no caso do grupo, positivo e almejado) do Brasil para a Alemanha, se sobressai a noção de aprendizagem de uma língua estrangeira à uma melhora de vida por meio "do contato com algo previamente entendido e encarado como superior ao que já possuímos" (RAJAGOPALAN, 2003, p. 67). Em outras palavras, o que se evidencia é o alçamento (do aprendizado) da língua alemã à conquista de uma vida melhor, superior àquela que ocorre em território e idioma brasileiros. Aqui o aprendizado do alemão simboliza um acesso não só a uma nova perspectiva de compreender o mundo, mas também a outras possibilidades materiais de existência e de experenciar uma nova realidade distinta e aparentemente melhor que a realidade brasileira, já que, conforme o exposto por Bohunovsky (2005), a imagem da língua alemã - e por extensão, um dos centros ao qual ela pertence, nesse caso, a Alemanha - carrega um suposto atributo de superioridade.

Em síntese, após a exposição da análise, podemos considerar que duas das três categorias evidenciadas anteriormente se sobressaem entre as imagens da língua alemã apresentadas pelos aprendizes. A principal é a língua como imagem cultural, pela qual eles entram em contato com a Alemanha, sua história e produtos culturais. Todas as associações feitas são estereotipadas e partilhadas pela maioria. Essas conexões, de acordo com Coelho e Simões (2017), apoiadas em autores como Moore (2001) e Boyer (1998), provém das representações das línguas que são construídas socialmente e compartilhadas pela comunidade, na qual os aprendentes se encontram, e são imagens estabilizadas. A segunda é o laço que os próprios estudantes estabelecem entre si e a língua, acrescentando uma dimensão afetiva, conectando a língua estrangeira aos seus anseios pessoais e profissionais e, o qual acreditamos, ser a principal motivação destes enfermeiros para o aprendizado da língua. 


\section{CONSIDERAÇÕES FINAIS}

Neste trabalho apresentamos um recorte de uma pesquisa em andamento sobre quais representações da língua alemã possuem aprendizes de um curso intensivo de alemão para fins profissionais. Discutimos a especificidade do curso de línguas direcionado a propósitos laborais e expomos como o curso em questão é organizado para cumprir tal objetivo. Uma vez que fazemos uso de métodos visuais como procedimento metodológico empregado na investigação, ocupamo-nos da reflexão dos diferentes sentidos dos conceitos de imagem e representação e do desenho como objeto de análise.

$\mathrm{Na}$ análise das produções visuais pudemos observar que há elementos em comum nos três desenhos examinados e que as imagens da língua alemã ali presentes podem ser subsumidas em três categorias: a primeira seria a língua enquanto imagem cultural associada a um único país; a segunda corresponde à língua alemã como objeto de ensinoaprendizagem e de sucesso profissional e, por fim, a terceira refere-se ao alemão enquanto objeto afetivo e de projeção pessoal. Como manifestamos anteriormente na análise com base em alguns autores, as imagens das línguas são estereotipadas e compartilhadas por uma comunidade linguística, sobretudo as correspondentes à primeira categoria e mostram-se pouco diversificadas. Mas elas também são construídas ao longo do processo de aprendizagem, no qual são acrescidas de certa subjetividade, que podem se manifestar, por exemplo, na motivação e estratégias para o aprendizado. E justamente por essas características, as imagens linguísticas permitem-se serem modificadas.

A partir da identificação destas categorias, nosso próximo passo consiste em refazer a atividade com os profissionais na etapa final do curso e a partir disso, examinar se estas representações persistem, se elas são alteradas e, em caso positivo, quais mudanças são percebidas, que outras imagens são adicionadas e, finalmente, em entrevistas com as aprendizes, perceber qual papel elas desempenharam no processo de aprendizado da língua alemã ao longo do curso, isto é, se elas mostram-se como um obstáculo à aprendizagem ou então como facilitadoras deste processo.

Um desafio que surge destas considerações é como estas imagens podem ser diversificadas, aqui também levando em conta, como já mencionado, o papel dos professores no manejo não só do material didático em relativizar certos estereótipos - que muitas vezes são apresentados nos próprios materiais -, mas também na comunicação de suas concepções pessoais e na sua postura de levantar discussões que acrescentem outras perspectivas, como, por exemplo, a concepção de alemão como uma língua pluricêntrica (AMMON, 2015), e ainda em buscar outras abordagens que ampliem os horizontes 
relacionados às imagens das línguas, para que estes sujeitos construam representações linguísticas mais diversas e plurais.

\section{REFERÊNCIAS}

AMMON, U. Die Stellung der deutschen Sprache in der Welt von heute. In: LeibnizInstitut für Länderkunde (ed.) Nationalatlas der Bundesrepublik Deutschland, vol. 11: Deutschland in der Welt. München: Elsevier, 2015, p. 110-111.

BOHUNOVSKY, R. Imagens de uma língua: reflexões sobre o ensino de alemão como língua estrangeira no Brasil. In: Pandemonium Germanicum, n. 9, 2005, p.327-344.

BOYER, H. Sociolinguistique. Territoire et objets. Paris: Delachaux et Niestlé, 1996.

L'imaginaire ethnosocioculturel collectif et ses representations partagées: un essai de modélisation. Travaux de Didactique du FLE, 39, 1998, 5-14.

CALVET, L.J. L'insécurité linguistique et les situations africanes. In: CALVET,L. J.; MOREAU, A.L. (Eds). Une ou des norms? Insécurité linguistique et norms endogens en Afrique francophone. Paris: Diffusion Didier Erudition, 1998. p. 8-28.

COELHO, M.; SIMÕES, A.R. As imagens das línguas de alunos do $2^{\circ}$ Ciclo do Ensino Básico: foco nas línguas curriculares. In: MELO-PFEIFER, S.; SIMÕES, A.R. (Orgs.). Plurilinguismo vivido, plurilinguismo desenhado: estudos sobre a relação do sujeito com as línguas. Instituto Politécnico de Santarém, 2017.

DIAS, J.R.B. Imagens da diversidade intralinguística no $1^{\circ}$ Ciclo do Ensino Básico. Dissertação de Mestrado. Aveiro: Universidade de Aveiro, 2005, 214p.

KUHN, C. Fremdsprachen berufsorientiert lernen und lehren. Kommunikative Anforderungen der Arbeitswelt und Konzepte für den Unterricht und die Lehrerausbildung am Beispiel des Deutschen als Fremdsprache. Tese de Doutorado. 452f. Setor de Filosofia da Universidade Friedrich-Schiller Jena, 2007.

MELO-PFEIFER, S. \& SCHMIDT, A. "Desenha-te a falar as línguas que conheces": imagens de crianças luso(fono)descendentes na Alemanha acerca da sua Competência Plurilingue. In Andrade, A. I. et al (org.), A diversidade linguística nos discursos e nas práticas de educação e formação. Aveiro: Universidade de Aveiro, 2014, p.159-182

MELO-PFEIFER, S.; SIMÕES, A.R. (Orgs.). Plurilinguismo vivido, plurilinguismo desenhado: estudos sobre a relação do sujeito com as línguas. Instituto Politécnico de Santarém, 2017. 
MOORE, D. Prefácio. In: MELO-PFEIFER, S.; SIMÕES, A.R. (Orgs.). Plurilinguismo vivido, plurilinguismo desenhado: estudos sobre a relação do sujeito com as línguas. Instituto Politécnico de Santarém, 2017.

PRIKOSZOVITS, M. Deutsch als Fremdsprache für den Beruf lernen - doch (ab) wann? Ein altersgruppen- und niveaustufenspezifischer Zugang zur Diskussion um die berufliche Ausrichtung von DaF-Curricula. In: Zeitschrift für Interkulturellen Fremdsprachenunterricht, 22, n. 2, 2017, p. 155-168.

RAJAGOPALAN, K. Língua estrangeira e auto-estima. In: RAJAGOPALAN, K. Por uma lingüistica crítica: Linguagem, identidade e a questão ética. São Paulo: Parábola, 2008, p. 65-70.

SHOHAMY, E. G.; WAKSMAN, S. Talking back to the Tel Aviv Centennial: LL responses to top-down agendas. In: HÉLOT, Ch.; BARNI, M.; JANSSENS R.; BAGNA, C. (Eds.). Linguistic Landscapes, Multilingualism and Social Change. Bern: Peter Lang, 2012, p. 109-125. 


\section{ANEXOS}

Anexo 1: Produção visual 1.

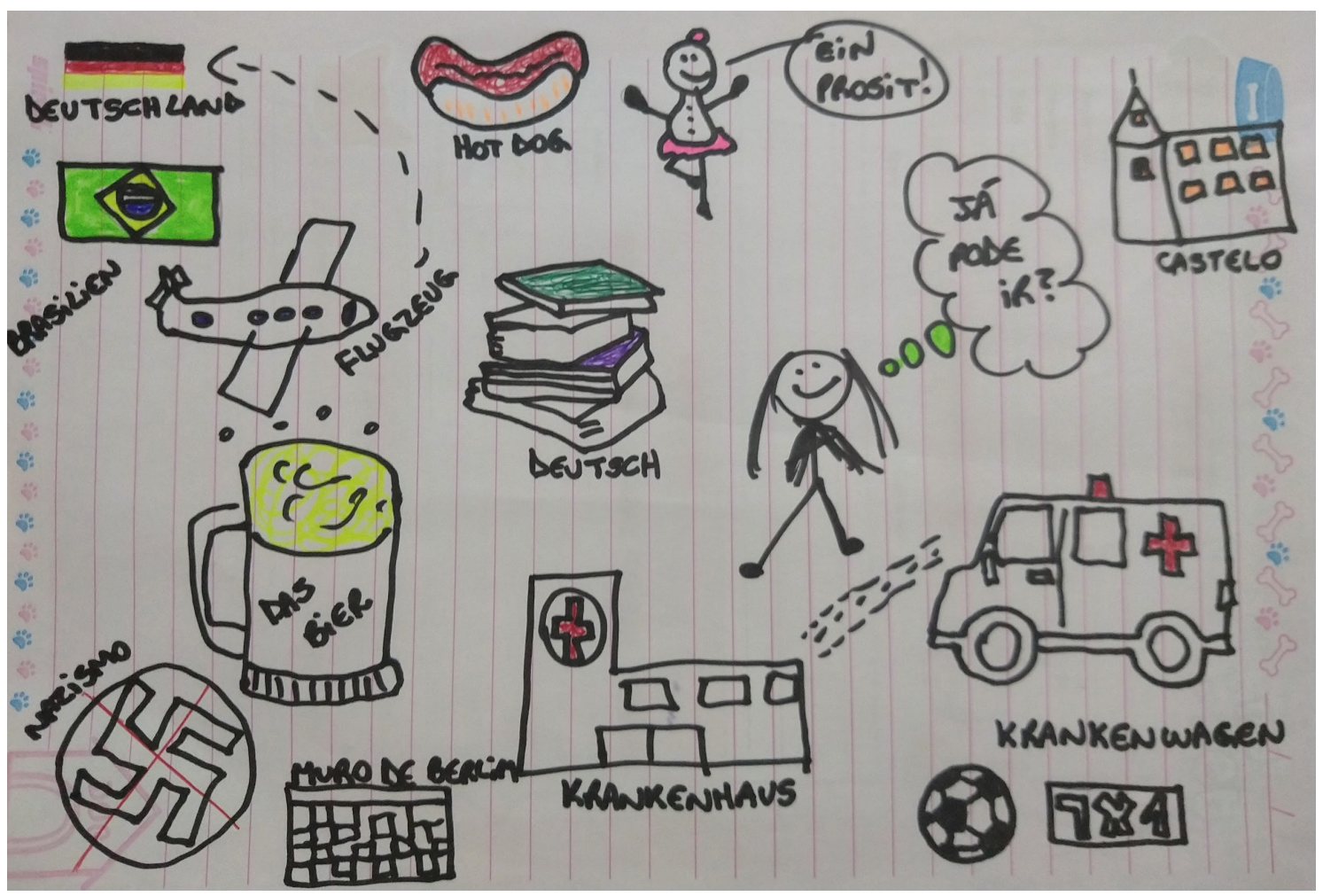

\#PraCegoVer: Imagem de uma folha de caderno com vários desenhos coloridos: bandeira da Alemanha com a palavra Deutschland e bandeira do Brasil com a palavra Brasilien, um avião entre elas e a palavra flugzeug. Uma caneca de chope escrito "das bier". O símbolo do nazismo com um X vermelho em cima e a escrita nazismo. Um muro e a escrita muro de Berlim. Um cahorro-quente e a escrita hot dog. Vários livros empilhados e a palavra Deutsch. Um hospital e a palavra Krankenhaus, uma estrada o liga a uma ambulância e a palavra krankenluagen. Uma bola de futebol e o placar 7 x 1. Uma bailarina alegre com um balão de fala "Ein Prost". Uma menina alegre e o balão de pensamento "Já pode ir?". Um castelo e a palavra castelo. 
Anexo 2: Produção visual 2.

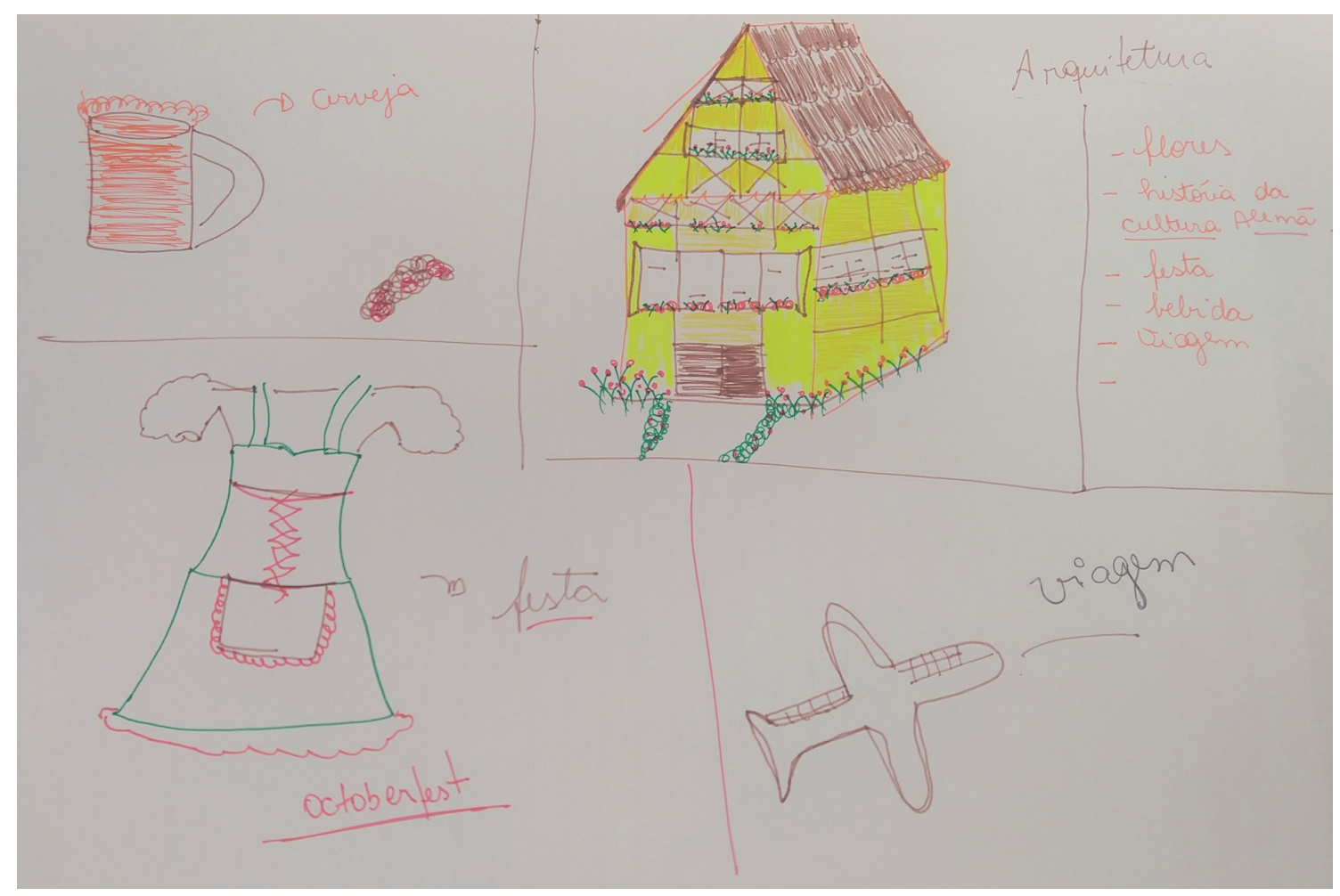

\#PraCegoVer: Desenho colorido organizado em cinco partes. $1^{\mathrm{a}}$. um caneco de chope e a escrita cerveja. $2^{\mathrm{a}}$. Uma casa amarela com telhado marrom, porta grande marrom e várias janelas com floreiras. Acima das janelas vários detalhes no formato de X. $3^{\mathrm{a}}$. Uma lista com as palavras: Arquitetura, flores, história da cultura alemã, festa, bebida, viagem. $4^{\mathrm{a}}$. Um vestido verde, com avental e corselet vermelhos, ao lado as palavras: festa e Octoberfest. $5^{\text {a }}$. Um avião e a palavra viagem. 
Anexo 3: Produção visual 3.

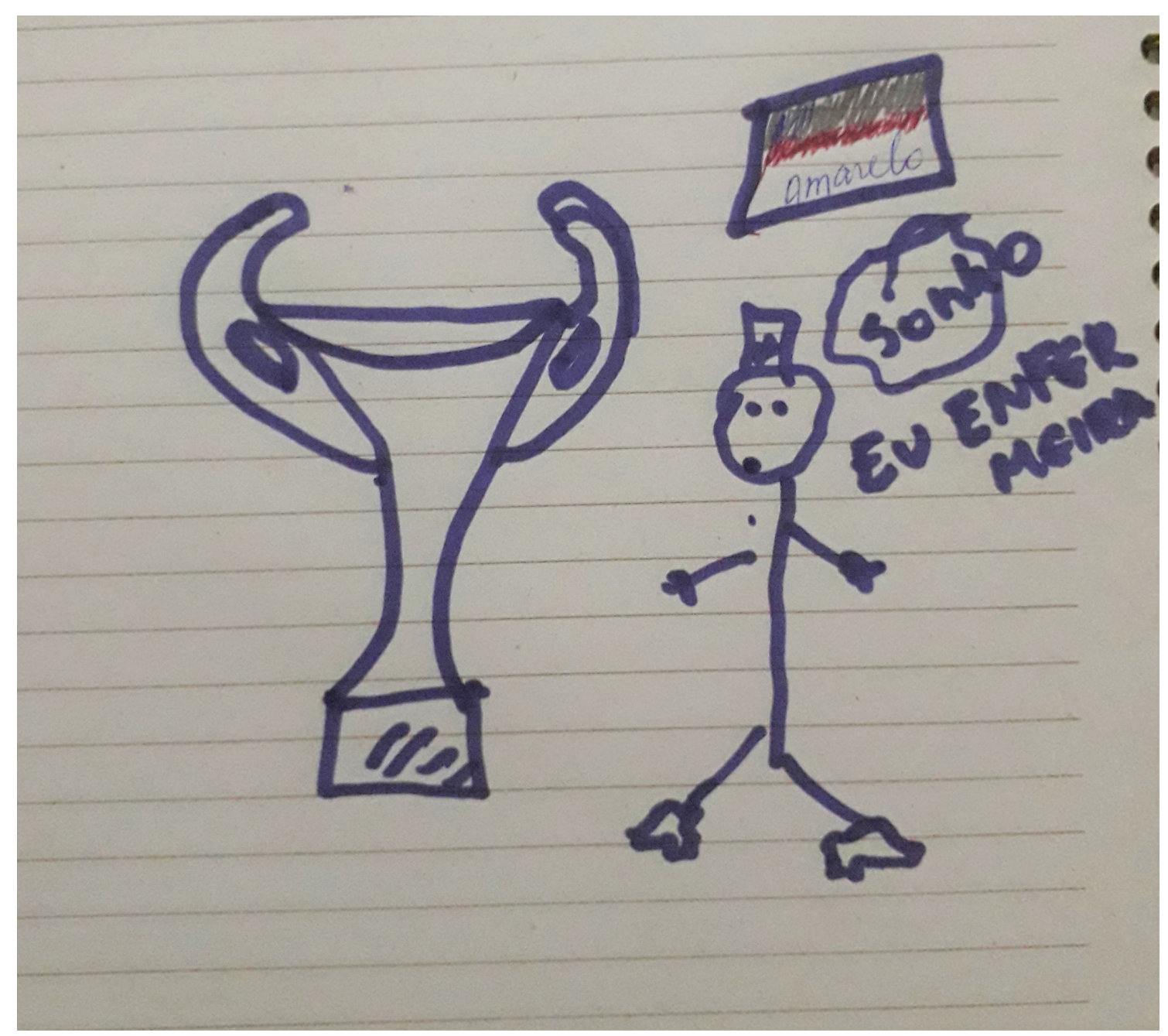

\#PraCegoVer: Desenho na cor azul. Um enorme troféu ao lado esquerdo e uma bandeira da Alemanha e uma pessoa ao lado direito. A pessoa usa um chapéu com o desenho de uma cruz, um balão com a palavra sonho e abaixo a frase "Eu enfermeira".

Recebido em: 12 out. 2020.

Aceito em: 27 jan. 2021. 